\title{
Microbiology Research Journal International
}

20(1): 1-7, 2017; Article no.MRJI.33323

Previously known as British Microbiology Research Journal

ISSN: 2231-0886, NLM ID: 101608140

\section{Isolation, Characterization and Antibiotic Susceptibility of Mycoplasma hominis and Ureaplasma urealyticum from Infertile and Pregnant Women in Lagos, Nigeria}

\author{
Eugene Ikeh ${ }^{1^{\star}}$, Mike Ebie $^{2}$, John Allanana ${ }^{1}$, John Oluwle ${ }^{3}$ and Nneoma Idika ${ }^{4}$ \\ ${ }^{1}$ Department of Medical Microbiology, University of Jos, Nigeria. \\ ${ }^{2}$ Army Headquarters, Area 7, Garki, Abuja, Nigeria. \\ ${ }^{3}$ Department of Obsteterics and Gynecology, Lagos University Teaching Hospital, Nigeria. \\ ${ }^{4}$ Nigerian Institute of Medical Research (NIMR), Yaba, Nigeria.
}

\begin{abstract}
Authors' contributions
This work was carried out in collaboration between all authors. All authors read and approved the final manuscript.

Article Information

DOI: $10.9734 / \mathrm{MRJI} / 2017 / 33323$

Editor(s):

(1) Ana Cláudia Coelho, Department of Veterinary Sciences, University of Trás-os-Montes and Alto Douro, Portugal.

Reviewers:

(1) Guadalupe García-Elorriaga, Mexican Social Security Institute, Mexico.

(2) Josiah A. Lennox, University of Calabar, Cross River, Nigeria.

(3) Akobi Oliver Adeyemi, Federal Medical Centre, Niger State, Nigeria. Complete Peer review History: http://www.sciencedomain.org/review-history/19168
\end{abstract}

Original Research Article

Received $10^{\text {th }}$ April 2017

Accepted $19^{\text {th }}$ May 2017

Published 23' May 2017

\section{ABSTRACT}

Background: Mycoplasma hominis and Ureaplasma urealyticum are potentially pathogenic agents, playing aetiologicroles in both genital infections and infertility. In human in-vitro fertilization systems, the presence of $U$. urealyticum in either semen or female genital tract results in a decline of pregnancy rate per embryo transfer as well as neonatal infections. M. hominis has been associated with bacterial vaginosis, pelvic inflammatory disease, postabortal fever, and a number of gynecological infections.

Aim: The aim of this study is to isolate, characterize and determine the antibiotic susceptibility of $M$. hominis and $U$. urealyticum isolates from infertile and pregnant women in Lagos, Nigeria. Materials and Methods: The samples were collected from Obstetrics and Gynaecology clinics of 
Lagos University Teaching Hospital and 68 Nigerian Army reference hospital Yaba. A total of 270 specimens of urine and HVS were collected from 135 women attending the clinics for routine consultations. One hundred and eighty HVS and urine specimens were from 90 married infertile women attending the clinics as part of a work-up for fertility investigations after failing to conceive for at least one year of unprotected sexual intercourse. Ninety HVS and urine specimens were from 45 pregnant women attending the clinics for routine antenatal care. None of the subjects expressed any symptom of genitourinary tract infections. All the specimens were inoculated into Mycoplasma broth and subsequently Blood Agar plates, incubated appropriately and identified. Antibiotic susceptibility tests were carried out on the 52 isolates. Polymerase chain reaction (PCR) was used to detect the organisms in all the collected specimens.

Results: Of the 90 HVS specimens collected from infertile women, $9(10.0 \%)$ were positive for M. hominis, while $21(23.3 \%)$ were positive for $U$. urealyticum. For the pregnant women using HVS specimens, $6(13.3 \%)$ were positive for $M$. hominis while $5(11.1 \%)$ were positive for $U$. urealyticum. The first void urine specimens gave lower values in both the infertile and pregnant women. Prevalence of $U$. urealyticum was higher in infertile women than in pregnant women $(p<0.05)$. The PCR technique gave higher values of $78.5 \%$ and $71.1 \%$ using HVS specimens for the infertile and pregnant women respectively for Mycoplasma/Urealyticum species. The antibiotic susceptibility test showed that all the isolates of $M$. hominis $(n=18)$ were sensitive to Tetracycline $(100 \%)$ and Ciprofloxacin $(100 \%)$ while all the isolates of $U$. urealyticum $(n=34)$ were sensitive to Tetracycline (100\%) and Erythromycin (100\%).

Conclusion: The significantly higher prevalence of $U$. urealyticum infection in infertile women $(23.3 \%)$ compared to the lower prevalence in pregnant women $(11.1 \%)$ may suggest that $U$. urealyticum can be incriminated in infertility. HVS specimen is preferred over urine specimens for the detection of Mycoplasma and Ureaplasma. Application of the PCR method, where affordable, is recommended for rapid and sensitive detection of Mycoplasma and Ureaplasma in HVS specimens. Tetracycline may be the antibiotic of choice, unless contraindicated, for the treatment of the infections, although the sample size was small.

Keywords: Prevalence; infertility; pregnancy; Nigeria; Mycoplasma hominis; Ureaplasma urealyticum.

\section{INTRODUCTION}

Infertility is considered when couples have been trying to achieve pregnancy with frequent sexual intercourse for at least a year without success [1]. Documented data revealed that approximately 72.4 million couples are infertile [1]. The causes of $25 \%$ of the cases of infertility are still unknown [2]. Majority of infertile females have inflammatory changes of the oviduct or the surrounding peritoneum and most of these alterations are caused by infections [3].

Generally, Mycoplasma hominis and Ureaplasma urealyticum have been isolated from genital mucosal surfaces, vagina and cervical parts of females $[4,5,6]$. U. urealyticum is a major cause of non-chlamydial and non-gonococcal urethritis, chorioamnionitis, acute prostatitis, vaginitis, cervicitis, preterm delivery and sepsis [6,7]. $M$. hominis is often associated with vaginitis, cervicitis, postpartum sepsis, pyelonephritis, preterm labour and premature birth $[8,9]$. Bacterial vaginosis is strongly implicated in female infertility and screening and treatment of bacterial vaginosis during the course of infertility management increased the rate of pregnancy [10]. The genital Mycoplasma represent a complex and unique group of microorganisms that have been associated with a wide array of infectious diseases in adults and infants. These microorganisms particularly $U$. urealyticum are potentially pathogenic species playing etiologic roles in both genital infections and infertility. In human in vitro fertilization systems, it was reported that the presence of $U$. urealyticum in either semen or female genital tract resulted in a decline of pregnancy rates per embryo transfer [11], as well as neonatal infections [12]. Similarly, $M$. hominis has been associated with bacterial vaginosis, pelvic inflammatory disease and post abortal fever as well as a number of gynaecological infections [13]. The isolation of these organisms in the diagnostic laboratories is cumbersome and takes several days to achieve. The identification from clinical specimens using Nucleic Acid Amplification Test is very expensive for routine purposes. We therefore decided to determine the prevalence of Mycoplasma infections among infertile and pregnant women in Lagos Metropolis, Nigeria; and to determine the 
susceptibility patterns of the isolates to some of the commonly prescribed antibiotics.

\section{MATERIALS AND METHODS}

\subsection{Ethical Issues}

The study was approved by the Ethical Committees of Lagos University Teaching Hospital (LUTH) and the 68 Nigerian Army Reference Hospital, Yaba (68NARHY). All the participants signed informed consent form to participate in the study.

\subsection{Inclusion Criteria}

All the specimens (Urine and HVS) were from married infertile women attending the Gynecology Clinics as part of a work-up for fertility investigations after failing to conceive for at least one year of unprotected sexual intercourse. Also included in the study were expectant mothers who were normal antenatal clinic attendees for routine medical attention. Subjects with any clinical symptom of sexually transmitted disease were excluded from the study.

\subsection{Sample Collection}

From July 2012 to September 2012, a total of $270 \mathrm{HVS}$ and urine specimens were collected from 135 women attending the clinics for routine consultations. One hundred and eighty of the specimens were from 90 married infertile women attending the clinics as part of a work-up for fertility investigations. Ninety specimens were from 45 pregnant women attending the clinics for routine antenatal care. The subjects were aged between 22-45 years. The HVS specimens were collected by clinicians using disposable speculum while the subjects were informed on how to collect the urine specimens devoid of contamination.

\subsection{Mycoplasma hominis and Ureaplasma urealyticum Isolation and Identi- fication}

The specimens were inoculated into the Mycoplasma transport/growth medium without delay. Clearly labelled specimens were treated by inoculating $0.1 \mathrm{ml}$ into $5 \mathrm{ml}$ of prepared Mycoplasma broth at the site of specimen collection and transported to the laboratory. The remaining urine specimens (about $10 \mathrm{ml}$ each) were stored at $-70^{\circ} \mathrm{C}$. Both the urine and HVS specimens were incubated for up to $48 \mathrm{~h}$ at $37^{\circ} \mathrm{C}$ in $5 \% \mathrm{CO}_{2}$ for Ureaplasma urealyticum and up to 5 days for Mycoplasma hominis. These were examined daily for turbidity as evidence of growth. Subsequently, the broth cultures were subcultured onto solid blood agar media and incubated at $37^{\circ} \mathrm{C}$ in $5 \% \mathrm{CO}_{2}$ for 24 to 48 hours for Ureaplasma urealyticum and up to 5 days for Mycoplasma hominis. Urea for urease activities and L-arginine for arginine utilization were used for biochemical tests. Strains of $M$. hominis ATCC 23114 and U. urealyticum ATCC 33175 were used as positive controls. Colonies presenting a fried egg appearance suggested the presence of $M$. hominis, while colonies that were brown and tiny indicated the presence of $U$. urealyticum. U. urealyticum also hydrolyzed urea while $M$. hominis metabolized the L. arginine [14].

\subsection{Polymerase Chain Reaction Confirmation of $U$. urealyticum and $M$. hominis}

A PCR technique was used to detect $U$. urealyticum and $M$. hominis. Two millilitres of urine and HVS broth specimens was used Ref: standard strains of $U$. urealyticum (ATCC 33175); M. hominis (ATCC 23114) and Clostridium difficile (ATCC BA-2155) were used.The PCR was carried out in an Eppendiof Nexus thermal cycler (E6331000025)with the following cycling parameters; an initial denaturation set up at $95^{\circ} \mathrm{C}$ for 10 minutes, followed by 30 consecutive cycles of denaturation at $95^{\circ} \mathrm{C}$ for 30 seconds, annealing at $56^{\circ} \mathrm{C}$ for 30 consecutive cycles. After this, a final extension at $72{ }^{\circ} \mathrm{C}$ for 5 minutes was carried out.

High vaginal swab (HVS) specimens and $2 \mathrm{ml}$ of first void urine from each subject were directly inoculated into $5 \mathrm{ml}$ of Mycoplasma broth, mixed and transported to the laboratory at the Nigerian Institute of Medical Research, (NIMR), Yaba, Lagos.

\subsection{Sample Preparation [15]}

Two milliliters of first void urine sample and HVS suspension from each of the subjects were put into a sterile $5 \mathrm{ml}$ tube and centrifuged at 13,000 rpm for 5 minutes. The supernatant is discarded and the cell pellets were resuspended in 50 microlitre of lysis buffer. After the homogenization, the cell pellets were incubated at $37^{\circ} \mathrm{C}$ for 15 minutes so as to lyse the cells and 
degrade the proteins. The samples were heated at $9^{\circ} \mathrm{C}$ for 10 minutes to inactivate the protease and then centrifuged at $13,000 \mathrm{rpm}$ for 5 minutes to sediment the cell debris [15]. The supernatants were transferred into new microcentrifuge tubes. Positive and negative controls were set up along side the kit controls.

The standard strains of control organisms are; Ureaplasma urealyticum - ATCC 33175, Mycoplasma hominis - ATCC 23114, strain PG 21, and Clostridium difficile - ATCC BA - 2155, Strain LBM 0801058. The primers My UUForward $5^{1}$ - TGG AGT TAA GTC GTA ACA AG3 and My UU reverse $r 5^{1}$ - CTA AGA TGT TTC ACT TCA CC-3, were obtained from NIMR, Yaba, Lagos.

\subsection{PCR Reaction Setup}

Twenty microliters of each of the universal PCR mix was transferred into a tube, 2.5 microliters of the universal primers and 2.5 microliters of the test samples were added and mixed gently using a voltex mixer. Positive and negative samples were set up alongside the controls. The tools were placed in a thermal cycler and were taken through the three steps of amplification procedure.

\subsection{Gel Electrophoresis Protocol}

Five microliters of the PCR product is added to 1.5 microliter of loading buffer, and mixed thoroughly. The samples and a DNA marker (1000 bp ladder) were loaded on the $3 \%$ agarose gel. Positive and negative controls were set up alongside the kit controls. Electrophoresis was allowed to run until the tracking dye has migrated $60-70 \%$ of the gel length. The gel was then stained with ethidium bromide and viewed with ultraviolet illumination.

The kit detects $10^{-9}$ microgram quantities of target DNA. Samples that were positive for the presence of Mycoplasmas showed a distinct band at $434-468 \mathrm{bp}$. The positive control exhibited a 464 bp band while no visible band was noticed in the negative control lane.

\subsection{Antimicrobial Susceptibility Test on the Isolates}

Antimicrobial susceptibility test was carried out on the isolates using the modified Kirby-Bauer method [16] with Tetracycline (30 $\mu \mathrm{g})$, Gentamycin $(10 \mu \mathrm{g})$, Erythromycin $(15 \mu \mathrm{g})$,
Streptomycin $(30 \mu \mathrm{g})$ and Ciprofloxacin $(5 \mu \mathrm{g})$. Statistical analysis was done using SPSS version 10 (computer software).

\section{RESULTS}

A total of 90 High Vaginal Swabs from infertile women and 45 HVS specimens from pregnant women were analysed using culture methods and PCR for M. hominis and U. urealyticum. Out of the $90 \mathrm{HVS}$ specimens from the infertile women, $9(10.0 \%)$ were positive for M. hominis while $21 \quad(23.3 \%)$ were positive for $U$. urealyticum. The urine specimens from both the infertile and pregnant women gave lower prevalences of $3.3 \%$ for $M$. hominis, $6.7 \%$ for U. urealyticum and $0.0 \%$ for $M$. hominis, $4.4 \%$ for $U$. urealyticum respectively (Table 1). HVS specimens yielded more isolates than the urine specimens $\left(X^{2}=72.174 ; P<0.05\right)$.

Table 2 shows the distribution of Mycoplasma/Ureaplasma organisms in infertile and pregnant women in the study area. Out of the 45 HVS specimens from the pregnant women, 32 (71.1\%) were Mycoplasma/ Ureaplasma. The 78 analysed urine specimens from the infertile women gave a prevalence of $58.9 \%$ of Mycoplasma/Ureaplasma infections. For the pregnant women, out of the screened 45 urine specimens $12(26.6 \%)$ were positive for Mycoplasma/Ureaplasma.

The antibiotic susceptibility patterns of the $M$. hominis and $U$. urealyticum is shown in Table 3. M. hominis showed $100 \%$ sensitivity to Tetracycline and Ciprofloxacin while U. urealyticum showed $100 \%$ sensitivity to Tetracycline and Erythromycin.

\section{DISCUSSION}

The results of our study showed that $M$. hominis and $U$. urealyticum infections are prevalent among the infertile and pregnant women in Lagos Metropolis, Nigeria. In this study both the HVS and Urine specimens were examined using culture and PCR techniques. The culture technique gave a prevalence, using the HVS specimens, of $M$. hominis (10.0\%) and $13.3 \%$ for infertile and pregnant women respectively. The urine specimens yielded lower values for $M$. hominis with a prevalence of $3.3 \%$ and $0.0 \%$ for infertile and pregnant women respectively. A prevalence of $6.7 \%$ for infertile women and $4.4 \%$ for pregnant women were recorded for $U$. urealyticum infection. The PCR technique 
expectedly gave higher prevalence of $78.5 \%$ and $71.1 \%$ using HVS specimens for Mycoplasma/Ureaplasma in infertile and pregnant women respectively. The urine specimens gave lower values of $58.9 \%$ and 26.6\% for Mycoplasma/Ureaplasma infection in infertile and pregnant women respectively. The urine specimens gave lower values of $58.9 \%$ and $26.6 \%$ for Mycoplasma/ Ureaplasma infection in infertile and pregnant women respectively. One possible explanation for the higher prevalences of these infections in infertile women is hormonal disorders which can lead to reduced levels of immunity and increased bacterial colonization and survival in the vaginal epithelium [17].

In addition to the considerably high prevalence of $M$. hominis and $U$. urealyticum infections in our study, several published report revealed various prevalence rates. Agbakoba et al. [17] reported a prevalence of $35.7 \%$ in women of reproductive age in Ibadan. The prevalence rate of $M$. hominis and $U$. urealyticum in HVS specimens ranged from 0 to $3.8 \%[18,19]$. The prevalence of $U$. urealyticum infection was $20 \%, 41.9 \%$ and $51.5 \%$ in South Africa, Italy and Africa respectively [18].

In a survey of 1000 female students at University of Calabar, Lennox et al. [20] showed that $70 \%$ were infected with vaginosis and vaginitis out of which $51 \%$ had single infection while $19 \%$ had mixed infections. The varied prevalence rates all over the world may be due to the use of only culture methods or PCR. In addition there are many factors that will affect the culture results

Table 1. Distribution of $M$. hominis and $U$. urealyticum in infertile $(n=90)$ and pregnant $(n=45)$ women in Lagos, Nigeria

\begin{tabular}{llll}
\hline Source & Organism & No. of isolates & Percentage \\
\hline Infertile women & M. hominis & 9 & 10.0 \\
HVS & U. urealyticum & 21 & 23.3 \\
& M. hominis & 3 & 3.30 \\
Urine & U. urealyticum & 6 & 6.70 \\
Pregnant women & & & \\
HVS & M. hominis & 6 & 13.30 \\
& U. urealyticum & 5 & 11.10 \\
Urine & M. hominis & 0 & 0.00 \\
& U. urealyticum & 2 & 4.40 \\
\hline
\end{tabular}

Table 2. Distribution of Mycoplasma/Ureaplasma species in infertile and pregnant women in Lagos, Nigeria using PCR

\begin{tabular}{llll}
\hline Source & Organism & No. of isolates & Percentage \\
\hline Infertile women & & & \\
HVS $(\mathrm{n}=65)$ & Mycoplasma/Ureaplasma & 51 & 78.5 \\
Urine $(\mathrm{n}=78)$ & Mycoplasma/Ureaplasma & 46 & 58.9 \\
Pregnant women & & & 71.1 \\
HVS $(\mathrm{n}=45)$ & Mycoplasma/Ureaplasma & 32 & 26.6 \\
Urine $(\mathrm{n}=45)$ & Mycoplasma/Ureaplasma & 12 & \\
\hline
\end{tabular}

Table 3. Antimicrobial susceptibility patterns of $M$. hominis and $U$. urealyticum isolated from infertile and pregnant women in Lagos, Nigeria

\begin{tabular}{|c|c|c|c|c|c|c|c|}
\hline \multirow[t]{2}{*}{ Source } & \multirow[t]{2}{*}{ Organism } & \multirow[t]{2}{*}{ No. of isolates } & \multicolumn{5}{|c|}{ Antimicrobial agent activities $\%$ sensitive } \\
\hline & & & Te & CN & $E$ & CPX & $\mathrm{S}$ \\
\hline \multirow[t]{2}{*}{ HVS } & M. hominis & 15 & $15(100)$ & $0(0.0)$ & $0(0.0)$ & $15(100)$ & $0(0.0)$ \\
\hline & U. urealyticum & 26 & $26(100)$ & $0(0.0)$ & $26(100)$ & $0(0.0)$ & $0(0.0)$ \\
\hline \multirow[t]{2}{*}{ Urine } & M. hominis & 3 & $3(100)$ & $0(0.0)$ & $0(0.0)$ & $3(100)$ & $0(0.0)$ \\
\hline & U. urealyticum & 8 & $8(100)$ & $0(0.0)$ & $8(100)$ & $0(0.0)$ & $0(0.0)$ \\
\hline Total & & 52 & $52(100)$ & $0(0.0)$ & $34(65.4)$ & $18(34.6)$ & $0(0.0)$ \\
\hline
\end{tabular}


such as the use of transport medium, the duration between the collection of the sample and the inoculation and the duration of incubation. The Nucleic Acid Amplification tests gave higher results due to its sensitivity and it is also a rapid test, although it is more expensive.

In our study, it was observed that $M$. hominis and $U$. urealyticum were detected more from HVS than urine specimens. This is in agreement with Taylor-Robinson [21] who reported that the numbers of isolates from urine specimens were usually 10 fold less than in swabs.

In vitro antibiotic susceptibility test showed that all the isolates of $M$. hominis and $U$. urealyticum were sensitive to Tetracycline (100\%). $U$. urealyticum isolates in addition to Tetracycline were all sensitive to Erythromycin, while all $M$. hominis isolates were also sensitive to Ciprofloxacin.

\section{CONCLUSION}

In conclusion, our research showed that $M$. hominis and $U$. urealyticum infections are prevalent in both the infertile and pregnant women in Lagos metropolis. Efforts, where feasible, should be made to detect the presence of these organisms during the work-up of cases of infertility and in pregnancy to prevent the adverse outcomes. We therefore recommend the precise monitoring of fertile and infertile females for the presence of $M$. hominis and $U$. urealyticum and treatment of positive cases to prevent diseases and possibly infertility.

The small sample size, and the lower number of recruited pregnant women compared with the infertile women are limiting factors in the present study. It is hoped that in future, a larger sample size will allow us to make definite conclusions.

\section{COMPETING INTERESTS}

Authors have declared that no competing interests exist.

\section{REFERENCES}

1. Boivin J, Bunting $L$, Collins JA. International estimates of infertility prevalence and treatment-seeking: Potential need and demand for infertility medical care. Hum Reprod. 2007;22(16): 1506-1512.
DOI: $10.1093 /$ hum re/dem046

[PubMed][Cross Ref]

2. Daar AS, Merali Z. Infertility and social suffering: The case of ART in developing countries. In: Vayena E, Rowe P, Griffin D, editors. Report of a meeting on Medical, ethical and social aspects of assisted reproduction. Geneva: WHO. 2001;16-21.

3. Wiesenfeld HC, Hillier SL, Meyn LA. Subclinical pelvic inflammatory disease and infertility. Obstet Gynecol. 2012; 120(1):37-43.

DOI: 10.1097/AOG.Ob 013e31825a6bc9 [PubMed][Cross Ref]

4. Capoccia R, Greub G, Baud D. Ureaplasma urealyticum, Mycoplasma hominis and adverse pregnancy outcomes. Curr Opin Infect Dis. 2013;26(3):231-240.

DOI: 10. 1097/QCO. Ob013e328360db58. [PubMed][Cross Ref]

5. Wang QY, Li RH, Zheng LQ. Prevalence and antimicrobial susceptibility of Ureaplasma urealyticum and Mycoplasma hominis in female outpatients, 2009-2013. J Microbiol, Immunol Infection; 2009-2013. [PubMed].

6. Al-Sweih NA, Al-Fadli AH, Omu AE. Prevalence of Chlamydia trachomatis, Mycoplasma hominis, Mycoplasma genitalium and Ureaplasma urealyticum infections and seminal quality in infertile and fertile men in Kuwait. J Androl. 2012; 33(6):1323-1329.

DOI: $10 . \quad 2164 /$ jandrol. 111.013821. [PubMed] [Cross Ref].

7. Zhu C, Liu J, Ling Y. Prevalence and antimicrobial susceptibility of Ureaplasma urealyticum and Mycoplasma hominis in Chinese women with genital infectious diseases. Indian J Dermatol, Venereology, Leprology. 2012;78(3):406-407.

[PubMed].

8. Aydin Y, Atis A, Ocer F. Association of cervical infection of Chlamydia trachomatis, Ureaplasma urealyticum and Mycoplasma hominis with peritoneum colonization in pregnancy. $\mathrm{J}$ Obstet Gynecol. 2010;30(8):809-812.

DOI: 10.3109/01443615.2010. 519063 [PubMed][Cross Ref]

9. Campos GB, Lobao TN, Selis NN. Prevalence of Mycoplasma genitalium and Mycoplasma hominis in urogenital tract of Brazilian Women. BMC Infect Dis. 2015;15(1):60.

[PMC free article][PubMed] 
10. Salah RM, Allam AM, Magdy AM. Bacterial vaginosis and infertility: Cause or association? Eur J. Obstet Gynecol Reprod Biol. 2013;167(1):59-63.

DOI: 10.1016/j. ejogrb. 2012.10.031

[Pub Med] [Cross Ref]

11. Reichart M, Kalane I. Bartoov B. In vivo and in vitro impairment of human and ram sperm nuclear chromatin integrity by sexually transmitted Ureaplasma Urealyticum. Infectious Biological Reproduction. 2000;(63):1041-1048.

12. Hentshel J, Abele-Horn M, Peters J. Ureaplsma Urealyticumin the cerebrospinal fluid of premature infants. Acta Paediatrica. 1993;82:690-693.

13. Yoshida T, Maeda S, Deguchi T, Ishiko H. Phylogeny- based rapid identification of Mycoplasma and Ureaplasma from urethritis patients. Journal of Clinical Microbiology. 2002;40:105-110.

14. Donald C. Lehman Connie R. Mahon. Mycoplasma and ureaplasma. In: Textbook of Diagnostic Microbiology, $4^{\text {th }}$ ed. 564-574. W.B. Sauders Company; 2011.

15. Kwok S. Procedures to minimize PCR product carry-over. In: PCR protocols: A guide to methods and applications (Innis MA, Gelfand DH, Sininsky JJ, White TJ, eds.) Academic Press, San Diego. 1990; 142-146.

16. Clinical and Laboratory Standards Institute: Methods for antimicrobial dilution and disk susceptibility testing of infrequently isolated or fastidious bacteria, approved guideline M45-A Wayne, Pa, CLSI; 2005.

17. Kornats'ka $A H$. Local humoral immunity in women with combined forms of infertility. Liksprava. 1998;4:82-84.

[PubMed].

18. Agbakoba NR, Adetosoye Al, Adewole IF. Presence of mycoplasma and ureaplasma species in the vagina of women of reproductive age. West Afr $\mathrm{J}$ Med. 2007;26(1).

19. Leli C, Mencacci A, Bombaci JC. Prevalence and antimicrobial susceptibility of Ureaplasma urealyticum and Mycoplasma hominisin population of Italian and immigrant outpatients. Infez Med. [PubMed]. 2012;20(2):82-87.

20. Lennox JA, Abbey SD, Udiba D, Mboto Cl, Ikpoh IS, Akubuenyi FC. Prevalence of vaginitis and vaginosis among University of Calabar female students. Journal of Public Health and Epidemiology. 2013;5(4): 167-172.

21. Taylor-Robinson D. Genital mycoplasma infection. Clin. Lab. Med. 1989;9:501-523.

(C) 2017 Ikeh et al.; This is an Open Access article distributed under the terms of the Creative Commons Attribution License (http://creativecommons.org/licenses/by/4.0), which permits unrestricted use, distribution, and reproduction in any medium, provided the original work is properly cited.

Peer-review history:

The peer review history for this paper can be accessed here: http://sciencedomain.org/review-history/19168 